\title{
RESEÑAS
}

\section{[La crisis no moderna de la universidad moderna]}

William Thayer.

Editorial Cuarto Propio,

Santiago, 1996,

239 páginas

¿Qué es este libro? ¿Es un reportaje, una crónica, un análisis de coyuntura; es acaso un compendio sintomatológico, una evaluación o un diagnóstico, una reflexión trascendental, un zurcido de fragmentos, un clip? Algún lector desconcertado pensará quizá, que es una pizca de cada cosa. Eso haría de este libro un pot-purri, un notorio centón. Aunque, lo concedo, esta impresión no carecería de asidero, sería más bien superficial. Desde luego, se trata de un libro de múltiples entradas. Pero no por eso es dócil a lecturas diversas. Una reticencia fundamental lo habita. El carácter evasivo de su estilo de escritura y pensamiento de testimonio de esa reticencia. Y ésta parece reservarse una única lectura, una única interpretación que atinaría a la verdad del texto. Parece curioso, en una obra que destaca por doquier las señas de una crisis abarcadora, abrumadora, de la verdad: señas de la débacle de lo universal concebible y de la indesmentible univocidad. Pero, a fin de cuentas, no es tan curioso. Este es un libro de filosofía, radicalmente; su único asunto es la verdad. Por eso habla de la universidad y de su crisis. Habla de la universidad, porque ella ha sido, en la historia occidental, ámbito privilegiado de la verdad, de su enseñanza y su búsqueda, espacio socialmente consagrado de su culto. Si es válido afirmar -como se hace con sobrada insistencia- que hoy, y por todas partes, la universidad está en crisis, no basta detenerse en los aspectos administrativos y organizacionales, en los problemas de gestión con los que suelen lidiar, más o menos ciegamente, las autoridades universitarias, ni tampoco en los desafíos y demandas de las sociedades en vísperas del tercer milenio, ni siquiera en los problemas inmanentes que plantea la dinámica del conocimiento y de la innovación tecnológica. Una consideración rigurosa exige hacerse cargo de lo que esa crisis significa para la verdad. Thayer supone que, en un cierto sentido, significa todo.

De ahí el "tono apocalíptico" que se vuelve, a ratos, dominante, equívocamente dominante en el libro. La lectura desprevenida creerá reconocer en él un desánimo radical: "el desánimo de esas enfermedades asintomáticas que deterioran a lo largo de tiempo, y que cuando nos percatamos de su existencia, nos han debilitado al punto que carecemos de moral para enfrentarlas"(169). Confesión de impasse irremontable, de enervación y debilidad (retengamos esta palabra), La crisis no moderna... aportaría su correspondiente dosis al narcótico con que se dopa buena parte de la intelligentsia finisecular; de la nuestra, también. ( $Y$, dicho sea de paso, no importa que su pose sea de amargura desvencijada o de frescura juvenil; como el ente, el desgano se dice -y se viste- de muchos modos.) Pero el apocalipsis es un estilo de la verdad. Este libro lo hace sentir enérgicamente. 
La mención de lo apocalíptico no sólo se justifica, pues, como atributo retórico, ni porque el texto recurra explícitamente a su concepto, que se destaca por última vez, como un gesto de abrumada confesión, en el epílogo de este "Epílogo". Y, dicho sea de paso, esa mención contiene además un guiño dirigido a la obra de Jacques Derrida, autor de un opúsculo con el título (de raigambre kantiana) D'un ton apocalyptique adopté naguère en philosophie, y de unos trabajos (no sólo especulativos) sobre la cuestión de la universidad, con los cuales visiblemente entronca este ensayo. La mención de lo apocalíptico, como el concepto más enfático de verdad del cual se dispone, puesto que habla de la verdad de cuerpo presente, quiere inducirnos a entender que asistimos, aun sin saberlo y sin siquiera percibirlo, al último apocalipsis: el de la imposibilidad de todo apocalipsis: "El pensamiento apocalíptico ya no puede resignificar(se) mediante ninguna representación del final" (201), escribe Thayer en el referido epílogo.

Es un libro reticente, decía. Pero no se trata de que su argumento permanezca recóndito. Las tesis que lo vertebran son, me parece, muy manifiestas. El libro enfoca la situación de la universidad en la transición. Sostiene que la transición no es un trance, sino una condición, pero una condición esencialmente evasiva. Bajo esa condición, la universidad estaría finiquitada, pero de manera tal que su fin podría mantenerse en un suspenso permanente. La relación fundamental de la universidad con el Estado y la nación, característica de la modernidad no rige más, en la medida en que el Estado mismo ha ingresado en la zona difusa de la transición. Lo que impera es el mercado, el "telemercado", si se quiere.

Desde luego, el empleo del término "transición" puede resultar engañosamente restrictivo si se lo refiere exclusivamente a los avatares y las parálisis de nuestro proceso particular. Sin perder de vista esta incidencia local, Thayer entiende la transición en términos generales, para no decir absolutos. La transición es el contexto de este texto, $y$, según éste, de todo texto posible hoy, sobre todo si se trata del texto universitario. La generalidad de este contexto es sui generis, en la medida en que no es conceptualizable. El contexto es escurridizo con respecto a toda aprehensión o fijación conceptual, porque no estriba en contenidos, sino en la unidad autogenerativa y abierta ( $y$, por eso, indefinidamente variable) de una performance de control y comunicación, de información y de intercambio. Cada concepto que pretenda circunscribirlo queda, al punto, circunscrito por él: cada descripción o exégesis, apenas enunciada, se convierte en un quantum de información virtualmente disponible en el ambiente mediático. Es lo que produce el proceso recíproco de la telematización del mercado y la mercantilización de la telemática: rasgo esencial de aquello que en términos de Thayer (tomados a préstamo de Felix Guattari) se denomina el "capitalismo mundial integrado". Por eso, no se puede sostener que el contexto sea una categoría, sino que acarrea la crisis de la categorialidad. Y esta última palabra no es anodina: las categorías representan el orden fundamental bajo el cual podemos pensar lo que pensamos, no importa lo que ello sea. La transición es, pues, forma vigente de la verdad: es la verdad como indiferencia, como un cierto tipo de indiferencia: precisamente, aquella que no hace ni deja hacer diferencia ( $Y$ éste es precisamente el apocalipsis peculiar, que, más que concebir, ilustra este libro). 
Pero el cautiverio contextual de los conceptos, del pensamiento que los piensa y que piensa en ellos, es sólo la mitad del hecho fundamental que se reportea en este libro. La otra mitad consiste en que ese cautiverio se preparaba en el fondo del proyecto de la propia universidad, de la universidad moderna. No sólo pertenece la universidad a la crisis, no sólo queda circunscrita en ella, sino también, y sobre todo, la ha premeditado sin cesar, nolens volens, hasta verla consumada sin reservas. La universidad ha sido la institución de la categorialidad. En el cuerpo de su nombre lleva tatuado este compromiso: la universidad es el sitio de lo universal, ya sea que se la afirme desde la confianza dogmática en un orden prescrito de los contenidos del saber o desde el proyecto enciclopédico o positivista de su progreso, ya sea que se la conciba como el reflejo del espacio de lo trascendental. Sólo ha faltado, a lo largo de su historia, que esta trascendentalidad se torne fáctica, que quede capturada por la facticidad. Es lo que ocurriría en nuestro presente transitivo. Y conste que esto no es lo mismo que la realización de una idea o que una profecía autocumplida... ¿suena todo esto muy sobreinterpretado, quizás? Thayer se apoya en un conjunto de análisis recientes (Derrida, Foucault, Lyotard, Baudrillard) que, de una manera u otra, destacan el proceso de la informatización de la sociedad como un cambio epocal que, entre otras cosas, pero muy decisivamente, viene a cumplir el ideal de una totalización cognitiva de las relaciones sociales, cuyo paradigma fue la ciudad universitaria": "La informatización de la sociedad nos obligaría a considerar que la ciudad universitaria dejó de ser una metáfora para referir el campus universitario separado del contexto con barreras y murallas. Tal campus se expandió como metrópolis y habitualidad ciudadana, se realizó literalmente como ciudad universitaria, como planeta informático-profesional" (64).

En todo caso, es claro que la universidad jamás ha podido ser concebida (ni, por supuesto, diseñada, ni fundada, ni practicada) sin una relación esencial, digo, y no meramente coyuntural (que es el modo en que regularmente se la entiende). El principio de la autonomía, que se suele afirmar como un ingrediente insuprimible de la esencia de la universidad, no hace más que confirmar expresamente esa relación, al darla por sentada, y sostener que, en su seno, la universidad sólo es posible a partir de la reserva de un núcleo, digamos, de inactualidad: una diferencia y un diferimiento de la actualidad del poder y de las urgencias pragmáticas, diferencia y diferimiento que tienen su eje en la densidad histórica del saber y sus prácticas y en la disposición de su propio pathos. En este sentido, la crisis de la que habla Thayer estriba, me parece, en que aquella relación se ha actualizado sin reservas, disipando, precisamente, lo que se tenía por esencia de la universidad, la cual se manifestaría hoy por hoy como resabio postrero y como hedor a muerto. Pero, claro, esa actualización (que, vista desde dentro de la universidad es harto notoria: basta considerar cómo se decide sobre la mantención, el cambio y la generación de los programas académicos) corre a parejas con una evanescencia de la especificidad del poder político y de la consistencia misma de lo social. La "esencia de la universidad" colapsa en la medida en que no tiene sobre que proyectarse, puesto que todo se ha vuelto juego 
de proyecciones y reflejos, contexto aparentemente ilimitado, ilimitado en cuanto aparente.

Un par de veces he evocado el nombre de Derrida. Las aseveraciones de Thayer que vengo a parafrasear fijan el punto en que sus devaneos se apartan de lo que bajo ese nombre se ha dicho sobre la universidad. En una conocida conferencia, Derrida concluía reivindicando una cierta distancia de la universidad respecto de la sociedad, tomando como motivo la suposición de que la Universidad mantiene con ella una relación "representativa", incluso "refleja". Pero este "reflejo" sólo es posible sobre la base de un tiempo de la "reflexión", que separa -que "disocia"- al espacio universitario del "tiempo social". El interés que guía a Derrida es afirmar que ese tiempo de reflexión inconmensurable con el tiempo social y sus urgencias, proporciona la oportunidad para una reflexión libre "sobre las condiciones mismas de la reflexión", si bien admite que ésta "es la oportunidad de un acontecimiento del que no se sabe si, presentándose en la Universidad, pertenece a la historia de la Universidad". Evacuada de su esencia, la universidad -u otra cosa alojada en ella- persistiría aún como acontecimiento, como una posibilidad puramente eventual. Pero es justamente esa reflexión sobre las "condiciones" lo que Thayer parece considerar como posibilidad clausurada, cegada, al menos, en el estilo que dio curso a la institución histórica de la universidad. La saturación del contexto excluiría, aparentemente, el pensamiento de la condición.

Esto querría decir que, consideradas las cosas en una perspectiva estricta, ni a partir de una esencia (una nueva fundación de su sentido, por ejemplo), ni tampoco como acontecimiento tendría curso ya la universidad. Ya no dispondría de ningún fondo (fuese éste sustancia o posibilidad); sobregirada históricamente, le convendría realinearse en una nueva estructuración de los saberes, de la cual ya no podrá formar más el centro. Tal sería el efecto general de una crisis -y ésta no es una crisis cualquiera, es la modernidad como crisis, y es la crisis como talque ha terminado reventando desde dentro: "Tampoco se trataría de una crisis de conceptos ante la irrupción de nueva categorización universitaria de relevo; de la emergencia y reposición de un discurso frente a la derrota de otro. Se trataría más bien de la crisis del discurso, de lo categorial en cuanto tal. Crisis de la filosofía que no puede, por lo mismo, ser controlada ni regulada desde el discurso. Al menos no desde el discurso filosófico, para dejar abierta la posibilidad de otro discurso, no filosófico, que pudiera hablarnos de la universidad. Carecemos de categorías para analizar el acontecimiento de la crisis de las categorías -incluida la categoría de <<crisis >>, tan recurrente en este escrito-." (44s).

No necesito decir el riesgo que percibo en estos asertos; una lectura desconcertada, como la que imaginaba al principio, y, más aun, una lectura desprevenida, podrían colegir de ellos el cierre total de la reflexión. Y yo diría que semejante riesgo, quiérase o no, está latente en este libro. Entiendo también que el lugar desde el cual se anuncia el riesgo no es desdeñable; se trata, no ya de los principios o las condiciones de posibilidad de la reflexión, sino del espacio en que ésta tiene, inexorablemente, que residir y desplegarse, espacio en que han de darse, cuanto menos, sus condiciones de efectividad: la lengua misma. Los 
planteamientos de Thayer surgen, en buena medida, de una cierta experiencia catastrófica de la lengua, que le hurta el suelo a las posibilidades del discurso. De ahí la pregunta insistente. "¿Cómo hablar... no universitariamente de la universidad? ¿Cómo prevenirnos de su estilo para, una vez ganándole las espaldas, cobrar autonomía teórica a su respecto? ¿Y cómo, en caso de lograrlo, hacernos oír por ella?" (65). Se creerá que ésta es una pregunta formulada a claustro cerrado. Lo será, con tal que no se piense que ella sólo concierne a lo que restrictivamente llamamos "universidad": ya se ha sugerido antes el tipo de ampliación de su concepto bajo el cual supone Thayer que hoy es imprescindible tratar la cuestión de lo universitario. En verdad, ésta es también una pregunta en la que resuena un conocido título derridiano: "Cómo no hablar"; "¿cómo hablar no universitariamente de la universidad?" implica, entonces, la pregunta "¿cómo no hablar -hoy- universitariamente, en general?" Lo que equivale a decir que la experiencia catastrófica de la lengua a que me refería es inseparable, en la percepción de Thayer, de una catástrofe de la experiencia, que se cumple, ante todo, con su conversación informática en archivo: "La experiencia sería aquello en lo cual toda información se funda; la información sería aquello en lo cual toda experiencia se borra. (...) La informatización o modernización cabal de la realidad traería consigo el olvido de la experiencia. "(63).

Doble catástrofe, pues, que nos sitúa en el espacio de la debilidad, esto es, en el espacio de la lengua como debilidad, de su salida de madre, aparentemente, sin vuelta. Digo esto, porque, bien entendida, es decir, comprendida a partir de la madre, la lengua es el espacio de conflicto agudo entre lo categorial y lo experiencial. Una lengua fuerte es una lengua que puede instalar ese espacio e instalarse en él. Y no, meramente, con el propósito de reivindicar determinadas experiencias contra la categorialidad, o de ejercer el vigor reductivo necesario para organizar la experiencia categorialmente, sino que es fuerte una lengua que logra sobrevivir en ese conflicto, que logra mantenerse en esa tensión y hacérsela presente a quienes actúan en ella, a quienes la habitan. La debilidad de la lengua tiene que ver con el hecho de que la incomposibilidad entre lo categorial y la experiencia ya no se vive como estímulo, sino como desgano.

Inseparablemente unida a la pregunta por la lengua con que se abre la exposición de Thayer, está la pregunta por el pensamiento con la cual se cierra. Es claro que, con el planteo del autor, ambas han de tener una sola respuesta, compleja. La última pregunta se formula a partir de una premisa general, en la cual volvemos a advertir la idea de transición que hemos comentado antes: "No es posible pensar el presente universitario, ni el presente en general" (198). He aquí la pregunta, entonces: "¿Qué tipo de pensamiento sería ése -si lo hubiera- que nos permita "pensar", desde los acontecimientos, la caída irrecuperable del pensamiento moderno en la contingencia?"(ibid.) De manera rapsódica, casi como quien toma apresuradamente notas taquigráficas de lo que está a punto de escapársele, el autor produce un catálogo de características de ese "pensamiento": "no categorial, ni reunidor. No teológico, por tanto, sino genealógico, ateo y disolvente. $\mathrm{Ni}$ cartográfico, ni universalista, ni totalizante; sino casuístico y ocasional. No narrativo, no argumental; sino alusivo, clip. No instrumental, no teleológico; sino 
dilatorio. Ni reflexivo, ni crítico; pero diferidor. No genérico ni disciplinar; más bien híbrido y nómade. No representacional ni trascendentalista; sino fáctico e inmanente. Un pensamiento eventual del evento que difiera a la universidad del reflejo condicionado mercantil en que se halla sumida, expropiándose de toda autoría" (ibid). Tiendo a discrepar del sentido que me parece colegir de este catálogo; no veo cómo este "pensamiento dispersivo" (si es válido darle este apodo) podría rescatarse de su inmersión total en la fascinada y fascinante obnubilación de la facticidad contextual, cuyo presente transitivo podría ser descrito en términos perfectamente similares a los que acabamos de leer. Por eso, no creo que lo que aquí se promueva sea aquello que en el mismo libro se denomina, con dejo de ambigüedad, la "universidad nietzscheana". En el momento en que se trata de decidir qué podría ser una universidad "resistente" en un contexto donde todo está en proceso de globalización me temo que esa suerte de universidad atea y ateleológica podría parecerse en los hechos (y eso es precisamente lo que cuenta cuando se trata del "pensamiento en la facticidad", como se titula el breve acápite final del que extraje las últimas citas), podría parecerse demasiado, digo, a un efecto -o incluso a la forma misma- de la globalización.

Pero no es ésta la única propuesta del libro. Advierto lo que sería su dimensión más abismática en la apelación, en la filosofía y como filosofía, a ciertos momentos que llevan el índice de una inconmensurabilidad. Momentos, también que son nombres, grandes nombres filosóficos, inscritos en el texto de Thayer como estelas o monumentos de una tensión aguda, entre los dos polos de lo categorial y lo experiencial, y que socavan, a la vez, el suelo temprano de la inauguración de la universidad y el tardío de su clausura. Así ocurre cuando se alude allí a Sócrates, el que no escribe, cuando se examina a Descartes, que se desprende de todas las palabras, cuando se considera a Kant, que establece el espacio de la reflexión como pura posibilidad, y que es, por tanto, un espacio para el cual ninguna palabra es propia, uno, más bien, en que toda palabra tendrá que ser juzgada -puesto que el juicio opera allí como la fuerza fundamental que permite constantemente volver a restablecer una relación con el lenguaje-, y cuando se habla de Nietzsche, como aquél que deshace genealógicamente todas las formas consolidadas del lenguaje, subvirtiendo su gramática. Y sería posible agregar todavía algunos nombres que no aparecen referidos de manera inmediata o principal en el texto, y que no por azar se agrupan bajo la noción del poema, la cual aparece, muy marcadamente, en un solo lugar del texto, un lugar temprano (28 s.), y nunca más vuelve a ser retomada; nombres como los de Benjamín, Heidegger, el ya mencionado Derrida u otros por el estilo (y habría que agregar, de seguro, a Wittgenstein). Me parece interesante que se apele justamente a un momento pre-universitario, "salvaje" o "bárbaro", y radicalmente filosófico, en el cual se anuncia quizás -y esto podría ser el otro apocalipsis del texto- algo así como un momento póstumo, un momento que no es, simplemente, un más allá de la crisis, sino el redespertar de su condición como aquello que falta en el contexto; más aun: como aquello cuya falta hace posible la saturación del contexto. 
Desde aquí puede entenderse quizá por qué impera en este libro por todas partes, la gramática de lo condicional ("habría", "sería", "podría", etc), es decir, la gramática de un presente condicional, que es este presente nuestro; un presente condicionado por el eclipse de la condición, que por eso mismo turba -turbaría- las formas en que nos habíamos habituado a hacernos cargo reflexivamente del presente, y, ante todo, la forma moderna de la crítica. Esa gramática quiere marcar el lugar en que nos hallamos: un lugar indeciso entre la fuerza y la debilidad, que excluye, desde luego, el apocalipsis de la condición (su presentación plena e inmediata), que impide también toda representación o imagen suya, y que mina, como ya dije, la posibilidad de reflexionarla y delimitarla críticamente (aun si fuese bajo el título -notoriamente equívoco- de "la condición posmoderna"). La condición, aquí, es padecida. Y la pasión es, precisamente, ese lugar indeciso entre debilidad y fuerza. Pero padecer la condición es acusar la necesidad que obra en ella, develarla incluso en el movimiento subrepticio de su solapamiento. Por eso mismo, ya es empezar a pensarla en su verdad, y es empezar a pensarla, también, como la figura de la verdad -esa figura, de la sustracción y del solapamiento- que nos atañe hoy esencialmente. En la forma de pathos, entonces, tiene que ver este libro con la verdad y con la necesidad, y así también es como quiere hacernos sentir aún, empecinadamente, ese doble e inseparable sello de la filosofía: elpathos de la verdad, la necesidad de pensar la condición.

\section{Pablo Oyarzún}

